\title{
Introduction to the Minitrack on Social Impact \& Information Systems
}

\author{
Jordana J. George \\ Texas A\&M University \\ jgeorge@mays.tamu.edu
}

\author{
Amber J. Young \\ University of Arkansas \\ AYoung@,walton.uark.edu
}

\author{
Sirkka L. Jarvenpaa \\ University of Texas at Austin \\ sirkka.jarvenpaa@mccombs.utexas.edu
}

\section{January 7, 2021, 9:00 AM US Central Standard Time Roundtable Discussion on Social Impact and Information Systems}

As the year 2020 draws to a close, we marvel at the tragedies, comedies, boredom, heroism, and innovation displayed by a world wracked by pandemics, political unrest, racial tensions, quarantine obstacles, and the reminder that our world is a global village where we all depend upon each other.

Despite the difficulties of 2020, a surprising number of researchers made the effort to codify their concerns about the world and the role of information systems within the social context. We received an impressive quantity of high quality papers, making the choice of which papers to include a difficult one. With thanks to all our authors and hopes that everyone will continue such impactful research, we list below the papers selected for the 2021 minitrack on Social Impact and Information Systems.

These papers generally fell into the following related themes: social inclusion, digital activism, digital platforms, and digital communications.

\section{Social Inclusion}

Our first SI paper, Can Digital Badging Support an Inclusive New Normal in Higher Education? examines alternatives for addressing education issues with a nod to racial disparities, which have been long standing and further exacerbated by the current pandemic. The second SI work is Stakeholder and Value Orientation in Digital Social Innovation Designing a Digital Donation Concept and an App to Support Homeless Neighbors. The action design research project explores the development of a digital fundraising system for a homeless population. Throughout the U.S., the proliferation of homelessness began in the 1980s and the societal problem continues to worsen. ICTs can facilitate better resourcing. Our third SI paper, Emancipation Research in Information Systems: Integrating Agency, Dialogue, Inclusion, and
Rationality Research, is a standalone literature review. The work, with its detailed tables and analysis, will be quite helpful for researchers engaging in IS critical theory and emancipatory systems work.

\section{Digital Activism}

Digital activism, the expression of social activism mediated through digital technologies, saw a banner year in 2020 with groups around the world expanding their digital political presence. Forced by the pandemic to communicate remotely, existing digital means were exploited and new ones forged. The first paper in this collection is Online Hate and its Routes to Aggression: A Research Agenda. The paper takes a hard look at the online antecedents of offline violence, extending the General Aggression Model. Our next work is Open or just Fragmented? Mobilization through Open Source Action Repertoires in the Social Movement of Bitcoin. This paper applies open source principles to the mobilization of social movements with some striking observations and implications. The last paper in this grouping, I Can't Breathe: How Digital Video Becomes an Emancipatory Technology, examines how digital videos from smartphones and body/dash cams have become de facto tools used by marginalized groups for establishing evidence.

\section{Digital Platforms}

The Digital Platform papers offer two very different views. The first, Extreme Situations, Measurement and Digital Infrastructures: The Case of the French Response to Mask Shortage During the Covid-19 Pandemic, uses a mixed methods approach and finds that extreme conditions produce extreme challenges in digital record keeping and measurement. 
Platform Workers under COVID-19: A Subaltern Perspective, our second platform paper, employs a unique lens that is rarely seen in IS research. The paper uses the current COVID-19 environment as a backdrop for digital gig workers fighting against marginalization and hegemonic forces.

\section{Digital Communications}

Our final paper, Pictographs, Ideograms, and Emojis (PIE): A Framework for Empirical Research Using Non-verbal Cues, offers a refreshing treatise on visual digital communication. The study focuses on Emojis that manipulate emotions and can have an impact for example on the believability of communications. Such visual communication can be important in crisis management and other societally impactful events.

We congratulate our authors and thank all the participants for their heartfelt work. As a minitrack that focuses on the positive, negative, and sometimes paradoxical impacts of ICTs on society, we recognize that our work and the works of our authors are a labor of love. As we strive to make the world a better place, we encourage IS researchers to continue their contributions. You are needed now more than ever.

Best wishes from your minitrack co-chairs, Jordana George, Amber Young, and Sirkka L. Jarvenpaa 